\title{
Kozak Yöresi Fıstıkçamı (Pinus pinea L.) ormanlarında fıstık verimi ile artım ve bazı meteorolojik olaylar arasındaki ilişkiler
}

\section{Dr. Mustafa BATUR}

Ege Ormancılık Araştırma Enstitüsü Müdürlüğ̈̈, Urla/IZMİR

İletişim yazarı/Corresponding author: mustafabatur@ogm.gov.tr, Geliş tarihi/Received:05.05.2015, Kabul tarihi/Accepted: 15.10.2015

$\ddot{O} z$

Bu çalışmada, Kozak yöresindeki fıstıkçamı ormanlarında fıstık veriminin çap artımı ve meteorolojik olaylarla ilişkileri araştırılmıştır. İlişkilerin ortaya konması için 2006-2011 yılları arasındaki yıllık çap artım verileri, meteorolojik veriler ve örnek ağaçlara ait fıstık verimleri kullanılmıştır.

Yapılan değerlendirmede; çap artımı ile fıstık verimi arasında önemli bir ilişki bulunamamıştır. Ancak, bazı meteorolojik olaylar ile fıstık verimi arasında ilişkilerin olduğu saptanmıştır. Özellikle, kabuklu fıstık verimi ile bir önceki yılın vejetasyon dönemindeki toplam yağış miktarı arasında $R^{2}=0,81$, iki yıl önceki vejetasyon dönemindeki toplam yağış miktarı arasında $\mathrm{R}^{2}=0,79$ seviyesinde ilişki saptanmıştır. Fistık veriminin kozalakların olgunlaştığı yıldaki meteorolojik olaylardan daha çok tozlaşma ve kozalakların büyüme dönemlerindeki meteorolojik verilerle ilişkili olduğu tahmin edilmektedir.

Anahtar Kelimeler: Fıstıkçamı, yıllık artım, fıstık verimi, sıcaklık, yağı̧̧, nem

\section{Relationships between pine nut Production, increment and some of meteorological data in Stone pine (Pinus pinea $L$.) forest of Kozak Region}

\begin{abstract}
In this study, the relations among annual diameter increment, nut yield and climatic events have been investigated in stone pine stands in Kozak Watershed.Annual diameter increments for years between 2006-2011, climatic data and nut yield of sample trees have been used to demonsrate these relations.

According to the results it is not determined any significant relation between nut yield and annual diameter increment. But there are some relations between climatic events and nut yield. Determination coefficents especially between yield of nut with shells and precipiation amount of one year ago and two years ago are $\mathrm{R}^{2}=0,81$ and $\mathrm{R}^{2}=0,79$ respectively. It is guessed that nut yield is more dependent to climatic events occured during one year old conelet growing period rather than mature cone period.
\end{abstract}

Key Words: Stone Pine, annual increment, pine nut production, temperature, fall, moisture

\section{Giriş}

Akdeniz iklim kuşağında doğal ve yapay ormanlar kuran Fıstıkçamı, geniş tepeli ve kazık kök sistemine sahip ibreli bir orman ağacı türüdür. Kozalakları üç yılda olgunlaşır. Ülkemizde Akdeniz, Ege, Marmara ve Karadeniz bölgelerinde yayılış gösterir.

F1stıkçamı ormancılık mesleği açısından son derece önemli bir türdür. Tohumundan elde edilen fıstık dünya pazarında rağbet gören çok değerli bir üründür. $\mathrm{Bu}$ sebeple, doğal ormanları yerel halk tarafından korunduğu gibi, birinci sınıf tarım arazilerinde bile bu ağaç türü dikilebilmektedir. Bugün ülkemiz ormanlarının büyük bir bölümü yerleşim alanlarından çok uzağa çekilmişken fistıkçamı ise yerleşim alanlarının hatta tarım alanlarının içinde bakılıp korunmaktadır. Nitekim, Kozak yöresinde köyler ve fistıkçamı ormanları birbirleriyle iç içe geçmiş durumdadır (Şekil 1).

Çam fıstığı yüksek pazar değeriyle ülkemiz

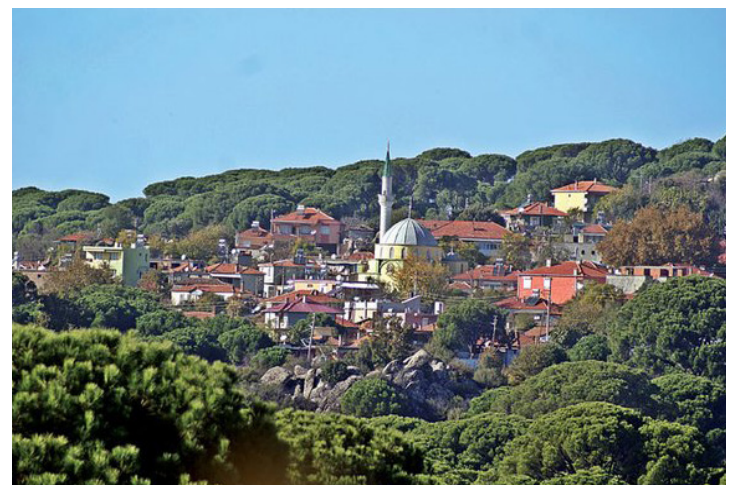

Şekil 1: Kaplan Köyü/Kozak Yaylası. Figure 1: Kaplan Village/Kozak Watershed.

ekonomisinde önemli bir yere sahiptir. Özellikle Bergama/Kozak yöresindeki halkın en önemli geçim kaynağı çam fıstığıdır.

Fıstıkçamı aynı zamanda odun verimi bakımından da yüksek değerlere sahiptir. Zira yapılan 
Relationships between pine nut Production, increment and some of meteorological data in Stone pine (Pinus pinea L.) forest of Kozak Region

bir araștırmada; birim alandaki artım/servet değerlerinin kızılçam ve karaçamdan daha yüksek olduğu görülmüştür (Batur ve Kiracıŏlu, 2014).

Bir orman ağacının ekonomik olarak değerli olması ormancılık hedefleri açısından son derece avantajlı olup stratejik olarak desteklenmesi gereken bir durumdur.

Son yıllarda hem yerel halk, hem de bazı bilimsel kaynaklar tarafından fistıkçamı ormanlarında verim düşüklüğü yaşandığı belirtilmektedir (Eltez ve ark. 2014; Bilgin, 2014). Hatta 30.05.2015 tarihinde bir araştırma önergesi ile TBMM meclis gündemine taşınmıştır (Güler, 2015). Ancak, fistık verimindeki bu düşüklüğün sebepleri ve süresi konusunda yeterli bilgi üretilememiştir.

F1stıkçamının bir orman ağacı ve tohumunun önemli bir gelir kaynağı olması nedeniyle, sorunun çözümü Orman Genel Müdürlüğü'nü yakından ilgilendirmektedir.

F1stık üretimindeki verim düşüklüğünün birçok nedeni olabileceği gibi bu nedenlerden bazılarının, ağaçlardaki fiziksel büyüme veya meteorolojik verilerdeki değişimler olabileceği de tartışılmaktadır (K1lc1 ve ark. 2011).

Bu tartışmalardan yola çıkarak, fistık çamında fistık verimi ile çap artımı ve meteorolojik verilerin birbirleriyle ilişkilerinin araştırılmasının sorununun çözülmesinde fayda sağlayacağı düşünülmüştür.

Fıstıkçamı ile ilgili sorunlara hızlı çözümler üretebilmek için bilimsel doğruluğu yüksek ve istatistik açıdan değerlendirilebilir veri kaynaklarımız maalesef son derece kısitlıdır. Hem ekonomik hem de stratejik ormancılık hedefleri bakımından önemli olan fistıkçamına ilişkin yeterince bilimsel veri toplanamamıştır. Ancak, hızlı bir değerlendirme yapılabilmesi için geçmiş yıllara ait verim değerleri ile verim düşüşüne sebep olabilecek faktörlere ilişkin verilere her zaman ihtiyaç olmaktadır. Bu bakımdan ormancılık ile ilgili sorunların çözümünde ar-ge çalışmalarıyla toplanan bilimsel verilerin ne kadar önemli olduğu da bir kez daha ortaya çıkmaktadır.

$\mathrm{Bu}$ doğrultuda, hızlı bir değerlendirme için, Kılcı ve ark. (2013) tarafindan 2006-2011 yapılan gübreleme denemelerindeki kontrol grubu ağaçlarından elde edilen verim değerleri bir firsat olarak düşünülmüștür. Bahsi geçen çalışmadaki kontrol grubuna ait işlem yapılmayan verim değerleri, 2006-2011 yılları arasındaki meteorolojik veriler ve ağaçlardan alınan yıllık artım değerleri ile ilişkiye getirilmiştir.

\section{Materyal ve Yöntem}

\subsection{Materyal}

Bu çalıșmadaki materyallerden birisi; Kılcı ve ark., (2013) tarafindan yapılan 2006-2011 yıllarını kapsayan gübreleme denemelerindeki kontrol grubu ağaçlarından bu araştırma için 2015 yılında alınan artım kalemleridir. Bahsi geçen çalışmanın kontrol ağaçları 5 adet olup herhangi bir işleme tabi tutulmamıstır. Kontrol grubundaki 5 adet ağacın 20062011 yılları arasındaki yıllık artımlarının her biri bir örnek olarak alındığında, istatistik olarak değerlendirilebilir 30 örnek $(5 \times 6=30)$ bulunmaktadır.

2006-2011 yılları arasındaki, ağaçtaki kozalak sayısı, kabuklu fistık verimleri ve doluluk oranlarına ait veriler ilgili çalışmadan alınmıştır.

2006-2011 yılları arasındaki bölgeye ait meteorolojik veriler ise Kozak Meteoroloji İstasyonundan elde edilmiştir.

\subsection{Yöntem}

Çalışma; arazi, laboratuvar ve istatistik analiz olmak üzere üç aşamada gerçekleştirilmiştir.

Çalışmada öncelikle 5 ağaçtan artım kalemi alınarak 2006 ile 2011 yılları arasındaki yıllık artımların ilkbahar ve yaz odunları ayrı ayrı ölçülerek kaydedilmiștir. İlkbahar ve yaz odunlarının yıllık halkaya katılım oranları hesaplanmıştır (Şekil 2).

Kontrol grubu ağaçlarından elde edilen verim değerleri ile 2006-2011 yılları arasındaki meteorolojik veriler ve ağaçlardan alınan yıllık artım değerleri arasındaki ilişkiler regresyon analizi ile test edilmiștir. Regresyon analizlerinde en iyi $\mathrm{R}^{2}$ değerleri elde edilerek sonuçlar yorumlanmıştır. Regresyon analizlerinde; 2006-2011 yıllarına ait ağaç başına kabuklu fistık verimleri, kozalak adedi ve doluluk oranları 30 adet yıllık çap artımı ve meteorolojik veriler ile ilişkilendirilmiştir.

Fıstıkçamı kozalaklarının olgunlaşması 3 yılda ger-

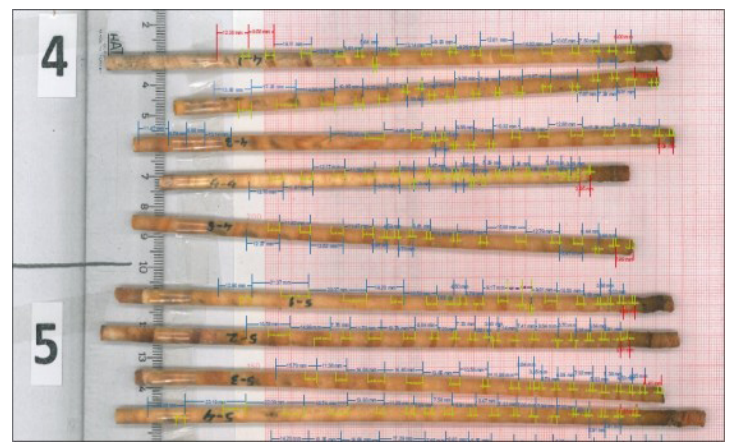

Şekil 2: Y1llık halka ölçmeleri.

Figure 2: The measurement of annual increment. 
Kozak Yöresi Fıstıkçamı (Pinus pinea L.) ormanlarında fıstık verimi ile artım ve bazı meteorolojik olaylar arasındaki ilişkiler

çekleştiğinden mantık olarak önceki yıllardaki polen oluşumu, döllenme durumu ve ülker oluşumu fıstık verimi ile ilişkilidir. Bu yüzden sadece kozalağın olgunlaşıp toplandığı yıl değil, aynı zamanda önceki iki yılın meteorolojik olayları da ilişkiye getirilmiştir.

Bu ilişkilendirmede:

$\checkmark \quad$ Kozalak adedi-yıllık artım

$\checkmark \quad$ Kabuklu fistık verimi- yıllık artım

$\checkmark$ Doluluk oranı-Y1llik artım

$\checkmark$ Kozalak adedi-ilkbahar odunu

$\checkmark \quad$ Kabuklu fistık verimi-ilkbahar odunu

$\checkmark$ Doluluk oran1-ilkbahar odunu

$\checkmark \quad$ Kabuklu fistık verimi-meteorolojik veriler

$\checkmark \quad$ Kabuklu fistık verimi-önceki iki yıla ait meteorolojik veriler

excel programına kaydedilerek bir analiz tablosu hazırlanmıştır.

Değerlendirmelerde eşlemenin solundaki değerler bağımlı değişken, sağındaki değerler ise bağımsız değişken olarak alınmıştır. Regresyon analizlerinden elde edilen en iyi $\mathrm{R}^{2}$ değerleri esas alınarak sonuçlar yorumlanmıştır.

\section{Bulgular}

\subsection{Artım ve fıstık verimi arasındaki ilişkiler}

Yıllık çap artımı ile ağaç başına olan kozalak adedi arasındaki ilişkinin regresyon katsayısı $\mathrm{R}^{2}=0,19$ 'dur (Şekil 3).

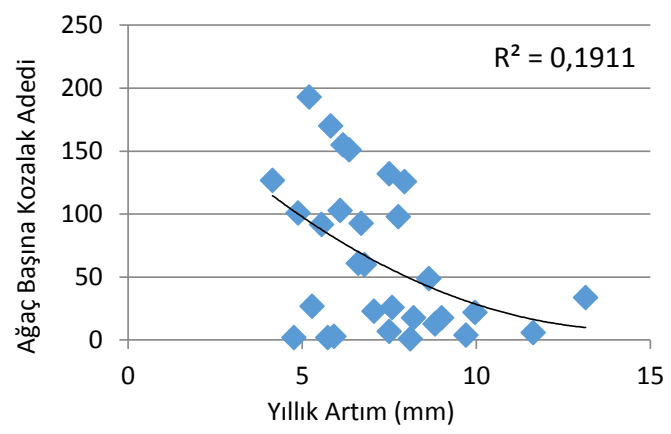

Şekil 3: Yıllık çap artımı-kozalak adedi ilişkisi.

Figure 3: The relationship between annual increment and cone numbers.

Verim ile çap artımı arasındaki ilişkiler zayıf bulunmuştur. Bu ilişkilerden ağaç başına kabuklu fistık verimi ile yıllık çap artımı arasındaki ilişkinin regresyon katsayısı $R^{2}=0,20$ ve tohumların doluluk oranları ile yıllık çap artımı arasındaki ilişkinin regresyon katsayısı $R^{2}=0,06$ olarak hesaplanmıştır.
Verim ile ilkbahar ve yaz odunlarının yıllık halkaya katılım oranları incelenmiş ve bu ilişskiler de zayıf bulunmuştur.

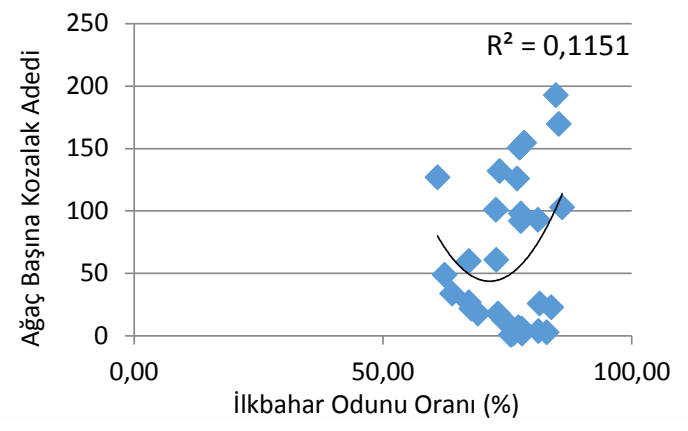

Şekil 4: İlkbahar odunu oran1-kozalak adedi ilişkisi. Figure 4: The relationship between ratio of spring increment and cone numbers

İlkbahar odununun yıllık halkaya katılım oranı ile ağaç başına olan kozalak adedi arasındaki ilişkinin regresyon katsayısı $\mathrm{R}^{2}=0,12$ 'dir (Şekil 4).

Ağaç başına olan kabuklu fistık verimi ile ilkbahar odununun yıllık halkaya katılım oranı arasındaki ilişkinin regresyon katsayısı $\mathrm{R}^{2}=0,01$ ve tohumların doluluk oranı ile İlkbahar odununun y1llık halkaya katılım oranı arasındaki ilișkinin regresyon katsayıs1 $\mathrm{R}^{2}=0,04$ 'dür.

\subsection{Fıstık verimi ve kozalağın olgunlaşma yılındaki meteorolojik veriler arasındaki ilişkiler}

Fıstık veriminin kozalakların olgunlaştı̆̆ meteorolojik olaylarla ilişkisinin ortaya konması için regresyon analizleri yapılmıştır. Bu analizlerdeki ilişkilerden:

$\checkmark$ Kabuklu fistık verimi -Vejetasyon dönemi uzunluğu $\left(\mathrm{R}^{2}=0,10\right)$

$\checkmark$ Ağaç başına fıstık verimi - vejetasyon dönemi toplam yağ 1 ş $\left(\mathrm{R}^{2}=0,45\right)$

$\checkmark \quad$ Kabuklu fistık verimi - Vejetasyon dönemi ortalama nem $\left(\mathrm{R}^{2}=0,40\right)$

$\checkmark$ Kabuklu fistık verimi - Vejetasyon dönemi ortalama sicaklik $\left(\mathrm{R}^{2}=0,07\right)$

$\checkmark$ Kabuklu fistık verimi - Vejetasyon dönemi minimum sicaklik $\left(\mathrm{R}^{2}=0,37\right)$

$\checkmark$ ve fistık verimi-yıllık ortalama sıcaklık $\left(\mathrm{R}^{2}=0,18\right)$

ilişkiler regresyon katsayıları değerlendirilerek önemsiz görülmüştür. Ancak, fıstık verimivejetasyon dönemi maksimum sicaklık $\left(\mathrm{R}^{2}=0,52\right)$ arasındaki ilişki kısmen dikkat çekicidir (Şekil 5). 
Relationships between pine nut Production, increment and some of meteorological data in Stone pine (Pinus pinea L.) forest of Kozak Region

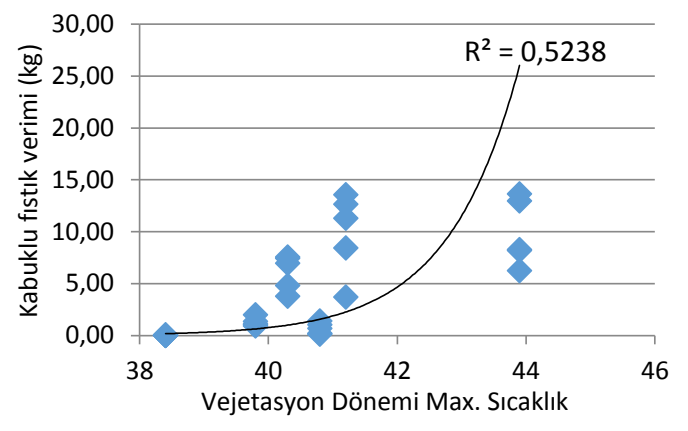

Şekil 5: Kozalak verimi- vejetasyon dönemindeki maximum sıcaklık ilişkisi.

Figure 5: The relationship between nut harvesting and maximum temperature in vejetation period.

\subsection{Fıstık verimi ile bir yıl önceki meteorolojik veriler arasındaki ilişkiler}

Olgun kozalak ve fıstık veriminin yüksek olması için bir önceki yılın iki yaşlı kozalaklarının sağlıklı olarak hayatiyetini devam ettirmesi ve kozalağa dönüşmesi gerekir. Bu nedenle olgun kozalak ya da fistık veriminin bir önceki yıla ait meteorolojik verilerle ilişkilendirilmesi faydalı olacaktır. Bu amaçla yapilan regresyon analizlerinde:

$\checkmark$ Kabuklu fistık verimi-vejetasyon dönemi uzunluğu $\left(\mathrm{R}^{2}=0,29\right)$

$\checkmark$ Kabuklu fistık verimi-vejetasyon dönemi minimum sicaklik $\left(\mathrm{R}^{2}=0,01\right)$

$\checkmark \quad$ Kabuklu fistık verimi-vejetasyon dönemi ortalama sicaklık $\left(\mathrm{R}^{2}=0,51\right)$

$\checkmark$ Kabuklu fistık Verimi-vejetasyon dönemi maksimum sicaklik $\left(\mathrm{R}^{2}=0,53\right)$

olarak hesaplanmış ve bu ilişkilerden fıstık verimivejetasyon dönemi uzunluğu, fistık verimi-vejetasyon dönemi minimum sicaklık ilişkileri önemsiz, fistık verimi-vejetasyon dönemi ortalama sicaklık ve fistık verimi-vejetasyon dönemi maksimum s1caklık ilişkileri dikkate değer görülmüştür.

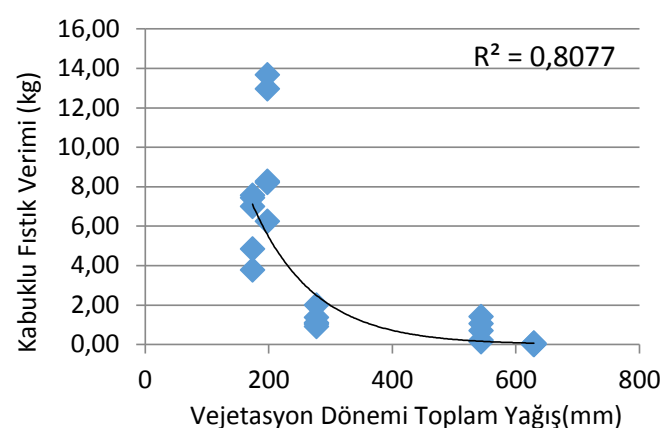

Şekil 6: Kozalak verimi-vejetasyon dönemindeki toplam yağış iliş̧isi.

Figure 6: The relationship between nut harvesting and total rainfall in vejetation period .
F1stık verimi ve vejetasyon dönemi toplam yağış arasında $R^{2}=0,81$ ve fistık verimi ve vejetasyon dönemi ortalama nem arasında $\mathrm{R}^{2}=0,75$ düzeyinde daha önemli bir ilişki görülmektedir (Şekil 6, 7).

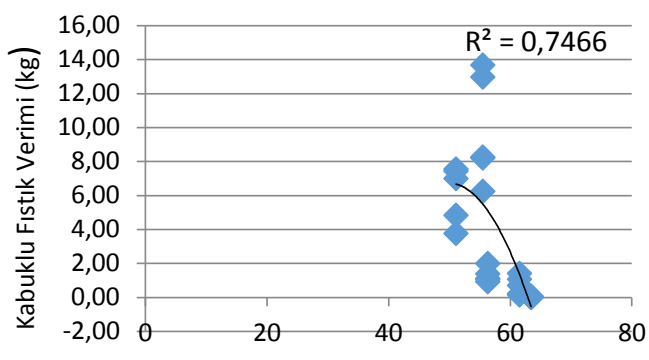

Vej. Dön. Ortalama Nem (\%)

Şekil 7: Kozalak verimi-vejetasyon dönemindeki ortalama nem ilişkisi.

Figure 7: The relationship between nut harvesting and moisture ratio in vejetation period.

\subsection{Fıstık verimi ile iki yıl önceki meteorolojik veriler arasındaki ilişkiler}

Kozalakların olgunlaşmasından iki y1l önce tozlaşma ve döllenme zamanıdır. Döllenmiş çiçeklerden oluşan ülker sayısının çok olması yüksek bir verimin de habercisidir. Bu yüzden iki yıl önceki iklim koşullarının döllenmeyi ve dolayısı ile ülker oluşumlarını etkileyip etkilemediği önemlidir. $\mathrm{Bu}$ varsayımdan hareketle ağaç başına olan fistık verimleri iki y1l önceki meteorolojik verilerle ilişkiye getirilmiş ve sonuçları yorumlanmıştır. $\mathrm{Bu}$ değerlendirmede:

$\checkmark$ Kabuklu fistık verimi-vejetasyon dönemi uzunluğu $\left(\mathrm{R}^{2}=0,10\right)$

$\checkmark \quad$ Kabuklu fistık verimi-vejetasyon dönemi minimum sicaklık $\left(\mathrm{R}^{2}=0,19\right)$

$\checkmark$ Kabuklu fistık verimi-vejetasyon dönemi ortalama sicaklık $\left(\mathrm{R}^{2}=0,30\right)$

$\checkmark$ Kabuklu fistık verimi-vejetasyon dönemi maksimum sicaklik $\left(\mathrm{R}^{2}=0,28\right)$

$\checkmark \quad$ Kabuklu fistık verimi-vejetasyon dönemi ortalama nem $\left(\mathrm{R}^{2}=0,69\right)$

olarak hesaplanmış ve bu ilişkilerden fıstık verimi-vejetasyon dönemi uzunluğu, fıstık verimivejetasyon dönemi minimum sıcaklık, fistık verimi-vejetasyon dönemi ortalama sicaklık, fistık verimi-vejetasyon dönemi maksimum sicaklık ilişkileri önemsiz, fistık verimi-vejetasyon dönemi ortalama nem ilişkisi ise dikkate değer görülmüştür.

F1stık verimi ve vejetasyon dönemi toplam yağış arasında ise $\mathrm{R}^{2}=0,79$ düzeyinde daha önemli bir ilişki görülmektedir (Şekil 8). 
Kozak Yöresi Fıstıkçamı (Pinus pinea L.) ormanlarında fıstık verimi ile artım ve bazı meteorolojik olaylar arasındaki ilișkiler

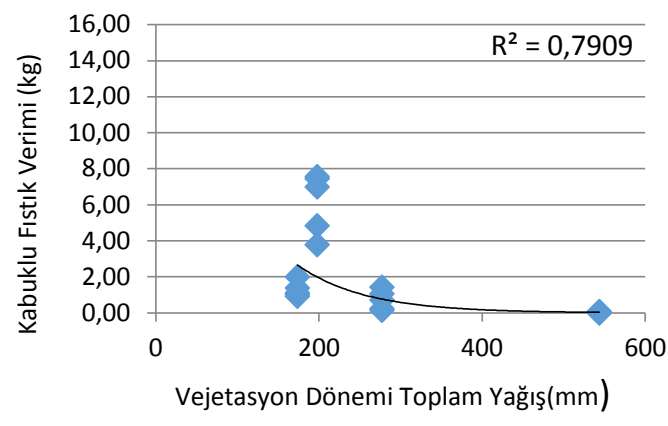

Şekil 8: Kozalak verimi-vejetasyon dönemindeki toplam yağış iliş̧kisi.

Figure 8: The relationship between nut harvesting and total rainfall in vejetation period .

\section{Tartışma ve Sonuç}

Y1llık artımların ve ilkbahar odunu katılım oranlarının fıstık verimi ile olan ilişkileri incelendiğinde; regresyon katsayılarının çok düşük olduğu görülmektedir. Diğer bir deyişle; fıstık verimine ilişkin veriler yıllık artım ve ilkbahar odunu oranlarının ortalama sadece \%1-3'lük kısmıyla açıklanabilmektedir (Şekil 3, 4 ). İlkbahar odunu oranlarının fistık verimine ilișkin verilerle bir ilișkisi olmaması sebebiyle yaz odununun da fistık verimiyle ilişkisi olmayacağı mantıken anlaşıldığından ayrıca analize tabi tutulmamıştır.

Genel ormancılık deneyimlerinin 1şı̆̆ında ağaçların hayatiyetlerini etkilemeyecek derecedeki çap artımı düşüşlerinin tohum tutma bakımından çok fazla etkili olmadığ ${ }_{1}$ söylenebilir. Çalışmadaki bulgular da bu tezi destekler niteliktedir.

Bulgular incelendiğinde verim ile ilişkisi en yüksek olan faktörün bir ve iki yıl önceki vejetasyon dönemindeki toplam yağış miktarı ve nem olduğu gözlenmektedir. Zira bu dönemlerde 2006 ile 2011 yılları arasında yıllık yağ ${ }_{1 S ̧}$ miktarı ve nem artarken verim ise düşmektedir (Şekil 6, 7, 8).

Önceki yıllara ait yağış miktarlarının verimle ilişkili olduğu daha önce yapılan bazı çalışmalarda da teyit edilmektedir. Özellikle yurtdışında yapılan bazı çalıșmalardaki fıstık veriminin tahminine yönelik denklemlerde yağış, önemli bir değişken olarak matematiksel formüllerde yer almıştır (Mutke ve ark. 2005; Calama ve ark., 2011).

Regresyon analizlerinden elde edilen sonuçlar; fistık veriminde döllenmenin olduğu ve ülkerlerin gelişme dönemindeki yağış yoğunluğunun sonraki yıllardaki kozalak verimini olumsuz etkilediği düşüncesini doğurmaktadır. Ancak, vejetasyon dönemindeki yağışın zamansal dağılımı da incelenmesi gereken bir durumdur. Çünkü yağışların tam olarak vejetasyon dönemindeki hangi fenolojik olay sırasında meydana geldiği ve fenolojik olayı nasıl etki- lediği bu çalışmada belirlenememiştir.

Fıstık verimi ile yağış arasındaki ters ilişki; yağışların ağaçların fiziksel büyümesine olumlu etkisi olsa da, koşulların 1lımanlaşarak mikroorganizma ve böcek faaliyetlerini artırmış olabileceğini düşündürmektedir. $\mathrm{Bu}$ yüzden mikroorganizma ve böcek faaliyetlerinin artması nedeniyle o yılki ülker ve iki yaşlı kozalaklarda kayıplar yaşanacağ1 tahmin edilebilir. Ağaçların ise bol yağışlı bu dönemde daha çok fiziksel büyümeye yöneldiği tahmin edilmektedir. Ayrıca daha kurak geçen yıllarda orman ağaçlarının tohum tutma kabiliyetini $\operatorname{artırdığ~} 1$ da bilinen bir ormancılık deneyimidir.

Verimin yıllık yağış ile ilişkilendirilmesinden çıkan sonuca göre üç yıl üst üste hafif kurak bir dönemin ülker oluşumu ve kozalak gelișimine olumlu yönde etki ederek fıstık verimini de artırabileceği düşünülmektedir.

Ülker dökülmelerinin veya bozulmasının azaltılması bakımından ise mantar ve böcek mücadele yöntemlerinin geliştirilmesi verim üzerine olumlu yönde etki edecektir.

Yağışların bol olduğu yıllarda ağaçların özellikle tepe büyümesi yapmasını olumsuz bir durum olarak değerlendirmemek gerekir. Çünkü tepenin büyümesi dal yoğunluğunun ve sürgün sayısının artması demektir. Bu da ileriki yıllarda koşulların sağlanması durumunda daha fazla dişi çiçek ve daha fazla kozalak oluşmasına olumlu yönde etki edebilir.

Çalışmada kullanılan örneklerin sayısı sınırlı ve dağılımı küçüktür. Verim düşüklüğüne yönelik tüm faktörlerin birlikte değerlendirilebileceği kapsamlı bir projeye ihtiyaç bulunmaktadır. Bu nedenle bazı meteorolojik verilerin fıstık verimi ile ilişkisi çıkmış olsa bile diğer faktörler ile bu etkinin artmış olabileceği gözden çıarılmamalıdır. Bu nedenle; fitopatolojik, entomolojik, bitki beslenmesi, hava kirliliği, budama gibi bazı silvikültürel müdahalelerin meteorolojik verilerle kombinasyonlarının birlikte değerlendirildiği en az 6-7 yıllık, uzun dönemli, eş zamanlı ve entegre bir ar-ge projesi fistıkçamında yaşanan verim dalgalanmalarının sebeplerini daha iyi ortaya koyacaktır.

Ülkemiz ekonomisi bakımından son derece önemli, aynı zamanda orman kaynaklarının korunması ve geliștirilmesinde stratejik bir öneme sahip olan fistık çamı ile ilgili bilgilere her zaman ihtiyaç olacaktır. Bu bilgilerin sürekli ve bilimsel doğrulukta olabilmesi için uzun süreli bir fıstıkçamı izleme programına ihtiyaç duyulmaktadır. Acil çözümler için hazırlanacak bu ar-ge projesinin daha sonra fistıkçamına özel kritik veriler toplanan bir izleme programına dönüştürülmesi faydalı olacaktır. Bu gibi kritik öneme sahip verilerin toplanması için küçük çapta, kalıcı veya geçici bölgesel veri 
Relationships between pine nut Production, increment and some of meteorological data in Stone pine (Pinus pinea L.) forest of Kozak Region

toplama istasyonları da kurulabilir.

\section{Kaynaklar}

Batur M., Kiracığlu Ö., 2014. Fistıkçamında (Pinus pinea L.) Hasılat ve Planlama, Fıstık Çamı, Ege Or. Arş. Enst. Md. Yayını, Yayın no: 74, Yayını, ISBN: 978-6054610-59-4, s: 154-177.

Bilgin F., 2014. Çam Fıstığı Ekonomisi ve Ticareti, Fıstık Çamı, Ege Or. Arş. Enst. Md. Yayını, Yayın no: 74, Yayın1, ISBN: 978-605-4610-59-4, s: 198-211.

Calama R., Tome M., Sanchez M., Miina J., Spanos K., Palahi M., 2011. Modelling non-wood forest products in Europe: a review. forest system. ISSN: 1131-7965, eISSN: 2171-9845.

Eltez Z. R., Kaplanoğlu E., Meriç K..M., Eltez S., 2014. Bergama Kozak Yaylası çam fistığı işleme tesislerinin durumu, sorunları ve çözüm önerileri, Ege Üniversitesi
Ziraat Fakültesi Dergisi, ISSN: 1018-8851.

Güler B. A., 2015. "Kozak Çam Fıstığı Sorunu Araştırma Komisyonu Kurulması Önergesi” TBMM.

Kılcı M., Sayman, M., Akkaş M.E., Bucak C., Parlak S., Boza Z., 2011. Kozak Havzası Fıstık çamı (Pinus pinea L.) Ormanlarında Kozalak Verimini Etkileyen Ekolojik Faktörler. Ege Ormancılık Araştırma Enstitüsü Yayınları Çeşitli Yayınlar Serisi No: 5.

Kılcı M., Akbin G., Sayman M., Özçankaya M. .İ, 2013, Kozak Yöresi Fistıkçamlarında Gübrelemenin Kozalak Verimine Etkisi Ege Ormancılık Araştırma Enstitüsü. Teknik Bülten No: 52 .

Mutke S., Gordo F.J., Gil L., 2005. Variability of mediterranean Stone Pine cone production: yield loss as response to climatic change. agric for met 132 . 